\title{
Simultaneous Adsorption of Iron and Sulfate lons with Biopolymers
}

\author{
Janek Weißpflog ${ }^{1}$, Christine Steinbach ${ }^{1}$, Dana Schwarz ${ }^{2}$, Simona Schwarz ${ }^{1}$ \\ ${ }^{1}$ Dept. of Polyelectrolytes and Dispersion, Leibniz-Institut für Polymerchemie Dresden e.V. \\ Hohe Straße 6, 01069, Dresden, Germany \\ weißpflog@ipfdd.de; steinbach@ipfdd.de; simsch@ipfdd.de \\ ${ }^{2}$ Department of Organic Chemistry, Faculty of Science, Charles University in Prague \\ Hlavova 2030/8, 12843 Prague 2, Czech Republic \\ schwarzda@natur.cuni.cz
}

\begin{abstract}
In this study, we investigated the simultaneous adsorption of iron and sulfate ions onto a natural biopolymer. Chitosan was used to remove anions and cations from aqueous solutions using adsorption in batch and column experiments. The adsorption process is based on two simultaneous running mechanisms, namely ionic interactions for the oxyanion sulphate and complexation for the heavy metal ion. In this context it is essential that both oppositely charged ions are present in the solution for a high performance adsorption. The adsorption capacities for iron ions on chitosan were very promising with a maximum adsorption capacity of $140 \mathrm{mg} / \mathrm{g}$ (for the batch experiments). The maximum adsorption capacity obtained for sulfate ions was $210 \mathrm{mg} / \mathrm{g}$. The column adsorption data pointed out that the rate of separation is $100 \%$ for iron ions and $83 \%$ for sulfate ions, respectively.
\end{abstract}

Keywords: Chitosan, Adsorption, Simultaneous Removal of Iron and Sulfate ions

\section{Introduction}

Since $19^{\text {th }}$ century brown coal is demounted in different regions of Germany. As a consequence of mining in the Spree region, pyrite (iron sulfide, $\mathrm{FeS}_{2}$ ) enters the rivers and streams, followed by oxidation. Eq. (1) represents the chemical reaction of the pyrite oxidation.

$$
\mathrm{FeS}_{2}+\frac{15}{4} \mathrm{O}_{2}+\frac{1}{2} \mathrm{H}_{2} \mathrm{O} \rightarrow \mathrm{Fe}^{3+}+2 \mathrm{SO}_{4}^{2-}+\mathrm{H}^{+}
$$

Iron and sulfate ions are water soluble and washed out from tipping areas as well as from naturally occurring pyrite layers. The concentration limit in drinking water of iron ions is $1,8 \mathrm{mg} / \mathrm{L}$ and of sulfate ions $200 \mathrm{mg} / \mathrm{L}$.

Iron(III) ions become visible (with iron concentrations higher than $3 \mathrm{mg} / \mathrm{L}$ ) the water in form of deposition, sedimentation and a red brownish sludge on the river banks and buildings. In addition, impairments of the water quality were detected via extraordinary high concentrations of sulfate ions. The sulfate concentration in different rivers in this region is higher than $1000 \mathrm{mg} / \mathrm{L}$. Both, the sulfate ions and the iron (III) ions formed by oxidation from iron(II) are problems for flora and fauna.

This leads to a considerable pollution of the surface water (i.e. iron hydroxide deposition) and causes problems with the drinking water abstraction due to the high iron concentration. The influences of the heavy metal ion pollution in waters are already observable. The deterioration of flora and fauna as well as of the constructions in water is significant. The issue of the iron entry into the waters increases in the case of closing of the open brown coal pit and the flooding of the abandoned open pit due to an increasing groundwater level and decreasing groundwater depression cones. Thus, the demand of removing the iron and sulfate ions in water increases due rising corrosion of cement and steel constructions and the thereby increasing requirement of reconstruction.

The biopolymer Chitosan has been used as an efficient adsorber material for heavy metal ions as well as for anions [1$5]$. 


\section{Experimental}

Chitosan in form of flakes with a deacetylation degree of $85 \%$ (product name Ch85/400/A2) from the company BioLogHeppe $\mathrm{GmbH}$ were used for the experiments. Chitosan flakes possessed a broad particles size distribution within the $\mathrm{mm}$ range. All investigations were performed in batch and column experiments. The iron(II) concentrations of the iron sulphate solutions varied between $100 \mathrm{mg} / \mathrm{L}$ and $10000 \mathrm{mg} / \mathrm{L}$ for the batch experiments. The concentration of the iron sulphate solution was $2500 \mathrm{mg} / \mathrm{L}$ for the column experiment. The adsorption time of the batch experiments was 24 hours hence within the adsorption equilibrium. The assignment of the heavy metal and anion concentration in solution was carried out with a DR6000 spectrophotometer from the company HACH Lange GmbH, Germany. The DR6000 microprocessor controlled spectrophotometer with a reference beam and a wave length region of 190 to $900 \mathrm{~nm}$. The instrument is appropriate for routine analysis and distinct applications (programmable). Particular associated cuvette tests for each ion are provided from the company. The instrument recognizes the specific cuvette test with a bar code on each standardized cuvette.

\section{Results and Discussion}

For an effective separation of iron and sulfate ions from contaminated ground waters and surface waters reasonable studies were taken with the naturally occurring biopolymer chitosan as sorbent. Chitin and its deacetylated derivate chitosan are obtained from crustacean rests of its shells or mushrooms allowing a first-time detected adsorption of both anions and cations. Using model systems (FeSO4(aq)) it was shown that the presence of metal ions has a positive effects on the adsorption of sulfate ions to chitosan flakes. Depending on the adsorption time and adsorption concentration batch experiments as well as experiments in an adsorption column were extensively characterized.

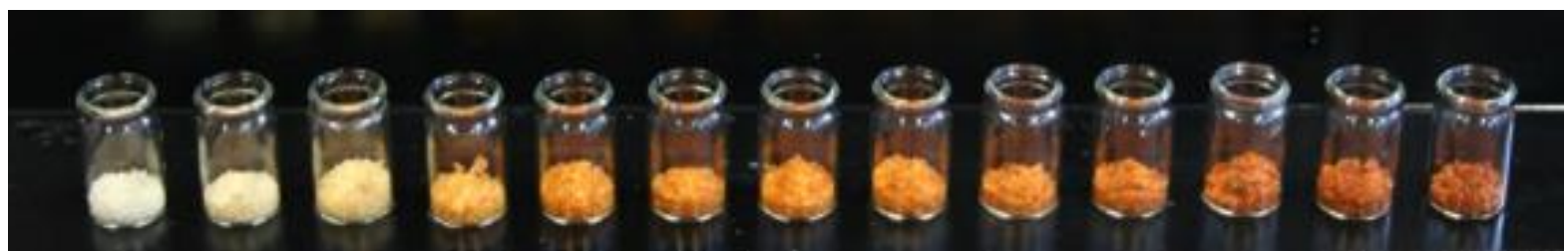

Fig. 1: Adsorption of $\mathrm{FeSO}_{4}$ on chitosan flakes with increasing of the iron sulfate concentration (from left to right hand side).

Figure 1 presents the adsorption of iron sulfate ions on chitosan flakes in batch experiments. Therefore, $30 \mathrm{~mL}$ of the produced iron sulfate solution were stirred with $1 \mathrm{~g}$ of the chitosan flakes. The adsorption time was 24 hours and the concentration of the iron sulfate solution has been varied for the initial concentrations of $100 \mathrm{mg} / \mathrm{L}$ up to $10000 \mathrm{mg} / \mathrm{L}$ from left to right hand side. A reference sample with zero iron sulfate is also shown leftmost. With increasing concentration of iron sulfate the adsorption onto the chitosan flakes increased and also the red brownish coloring became more intense. The maximum adsorption capacities were detected with $140 \mathrm{mg} / \mathrm{g}$ for iron ions respectively $210 \mathrm{mg} / \mathrm{g}$ for sulfate ions.

The simultaneous adsorption of iron and sulfate ions is schematically shown in Figure 2.

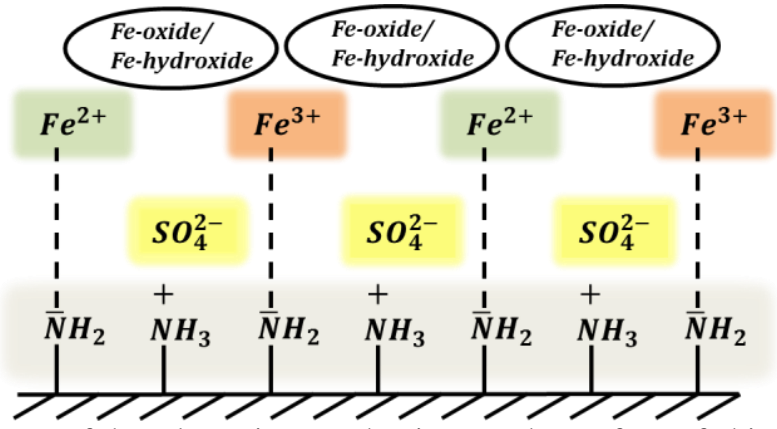

Fig. 2: Scheme of the adsorption mechanism on the surface of chitosan flakes.

The layer structure shows the alternating composition of positively charged iron ions and negatively charged sulfate ions. The adsorption mechanism also wants to illustrate that for a high content of atmospheric oxygen in water, the iron(II) 
ion gets easily oxidized to iron(III) ion. For the adsorption of sulfate ions the oppositely charged ion iron is essential, otherwise it is not possible to build a layer. Therefore, immediate actions such as the precipitation of iron ions by liming in affected areas strictly must be avoided.

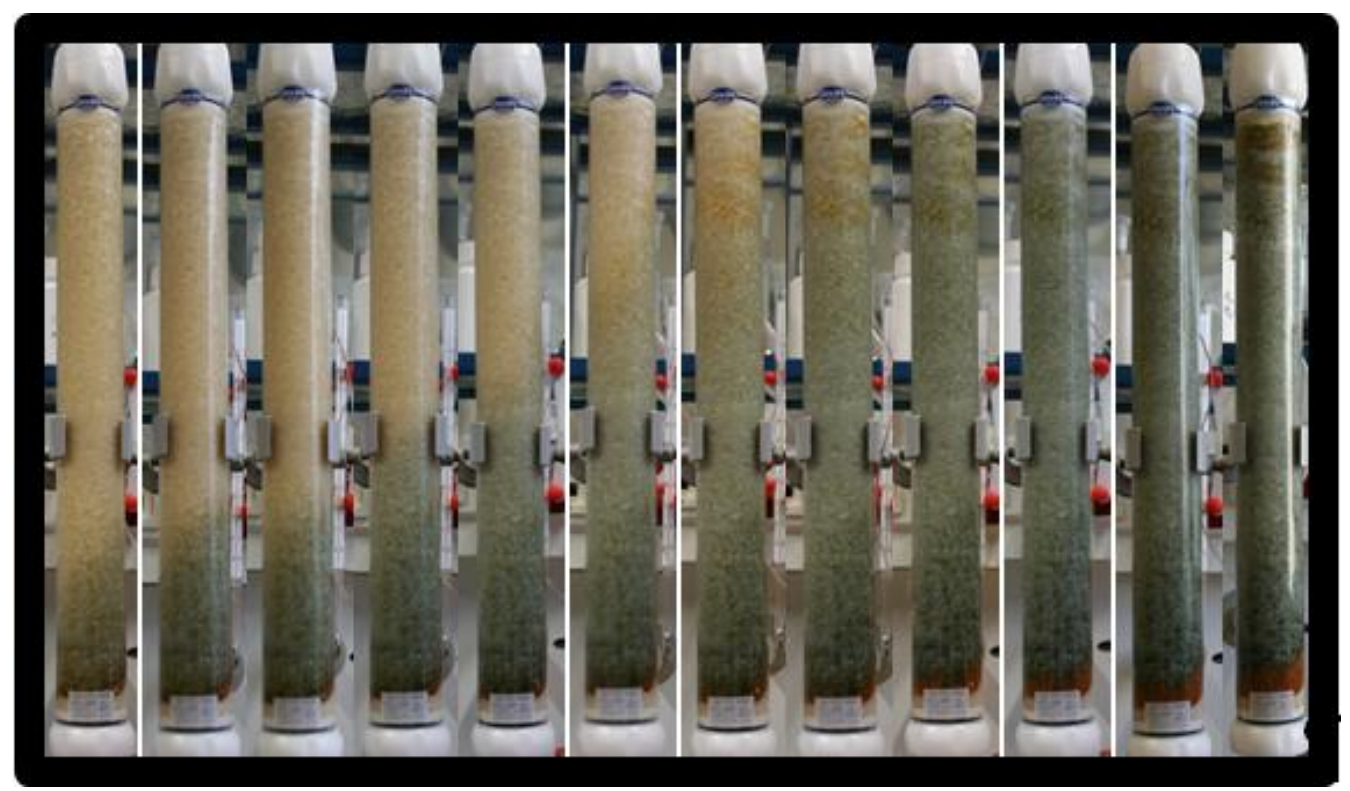

Fig. 3: Adsorption of iron sulfate ions on chitosan flakes in an adsorption column $\left(\mathrm{c}_{0}\left(\mathrm{FeSO}_{4}\right)=2500 \mathrm{mg} / \mathrm{l}, \dot{V}_{\text {pump }}=23 \mu \mathrm{l} / \mathrm{s}\right)$. Image of the adsorption experiment.

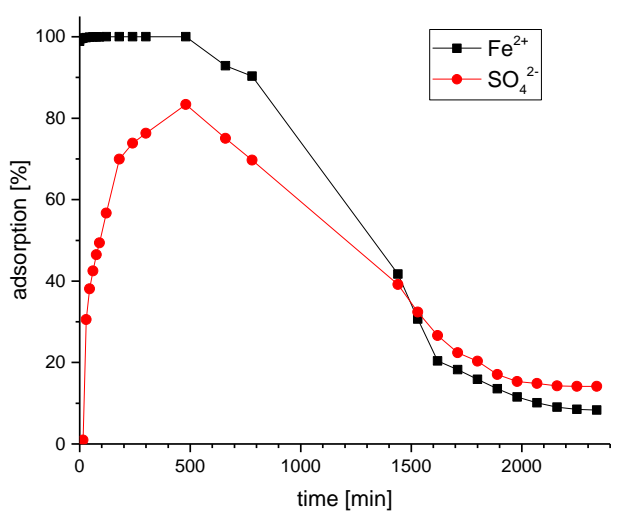

Fig. 4: Adsorption of iron sulfate ions on chitosan flakes in dependence of time, in an column experiment $\left(\mathrm{c}_{0}\left(\mathrm{FeSO}_{4}\right)=2500 \mathrm{mg} / \mathrm{l}\right.$,

$$
\left.\dot{V}_{\text {pump }}=23 \mu 1 / \mathrm{s}\right) \text {. }
$$

In addition to the batch studies investigations in the column were performed. Iron sulfate solution with a concentration of $2500 \mathrm{mg} / \mathrm{L}$ was pumped through a column packed with $90 \mathrm{~g}$ chitosan flakes and a flow speed of $23 \mu \mathrm{l} / \mathrm{s}$. The solution leaving the column was analyzed regarding the changes in iron and sulfate concentration (Figure 4). Similar to the batch experiments, an increase in color intesity of the chitosan flakes in dependence of the time can be observed (Figure 3). The lower part of the column changes the color first towards the red brownish iron(III) color which could already be noticed in the batch experiments before (s. Figure 1). In direction of the flow the increasing intensity of green color, which is characteristic for iron(II), can be observed. Here no oxidation interfered with the measurement. In dependence of the adsorption time, the maximum of adsorption for iron and sulfate ions can be detected after 500 minutes. In the beginning all iron ions adsorbed on chitosan. The maximum of the sulfate adsorption is $80 \%$. After 40 hours it is concluded that equilibria occurred with an adsorption rate between 10 and $20 \%$.

A significant problem which consists in the oxidation of the iron(II) ions to iron(III) ions could be eliminated by the column experiments. Based on this, the adsorption of sulfate ions was increased. SEM and EDX measurements indicated the 
simultaneous adsorption of Fe and S. The SEM images of chitosan after the adsorption process with the corresponding elemental distribution of $\mathrm{Fe}$ and $\mathrm{S}$ from EDX measurements can be seen in [4].

\section{Conclusion}

The limits of iron and sulfat ions in different regions in Germany are pass over. Chitosan as a natural non-toxic adsorber material has the ability to adsorb simultaneous the positively charged iron ions, as well as the negatively charged sulfate ions. The adsorption was investigated in batch and column experiments. The maximum adsorption capacities were $140 \mathrm{mg} / \mathrm{g}$ for iron and $210 \mathrm{mg} / \mathrm{g}$ for sulfate ions. The obtained adsorption capacities are comparable to other common adsorber materials.

\section{Acknowledgements}

The company BioLogHeppe GmbH is acknowledged for the supply of the chitosan powder and flakes applied in this investigation and for the helpful discussions.

\section{References}

[1] M. Mende, D. Schwarz, C. Steinbach, R. Boldt, S. Schwarz, "Simultaneous adsorption of heavy metal ions and anions from aqueous solutions on chitosan - Investigated by spectrophotometry and SEM-EDX analysis," Colloids Surf. A: Physicochem. Eng. Aspects, 2016, Available online: http://dx.doi.org/10.1016/j.colsurfa.2016.08.033

[2] S. Schwarz, M. Mende, D. Schwarz, "Chitosan - A natural adsorbent for copper ions," International Journal of Environmental Pollution and Remediation (IJEPR), vol. 4, pp. 15-19, 2016.

[3] S. Schwarz, C. Steinbach, M. Mende, D. Schwarz, R. Boldt, "Simultane Abtrennung von Eisen- und Sulfationen durch Kristallisation an Chitosanoberflächen," GWF: Wasser, Abwasser 12, 2016.

[4] S. Schwarz, C. Steinbach, D. Schwarz, M. Mende, R. Boldt, "Chitosan - The Application of a Natural Polymer against Iron Hydroxide Deposition," American Journal of Analytical Chemistry, vol. 7, pp. 623-632, 2016.

[5] M. Mende, D. Schwarz, C. Steinbach, R. Boldt, S. Schwarz, "The Influence of Salt Anions on Heavy Metal Ion Adsorption on the Example of Nickel," Journal of materials Chemistry. 